\title{
MATHEMATICAL MODELLING OF THE HEALD SHAFT
}

\author{
Martin Bílek, Šimon Kovář and Josef Skřivánek \\ Department of Textile Machine Design of Technical University of Liberec, Liberec, Czech Republic, Studentska 2, +420 485353174 , \\ E-mail: martin.bilek@tul.cz
}

\begin{abstract}
:
The manufacturers of weaving equipment recently endeavour to minimise the necessary designing plays in the weaving loom mechanisms. One of the mechanisms most exposed to stress is the shedding motion that defines the held-shaft stroke. Its end part is the heald shaft. The heald shaft constitutes a problematic assembly of the shedding motion. The design employed presently is characterised by dynamic impact loading caused by designing play in the suspension of healds into the heald shaft. During weaving cycle, the healds fly between the main beams of the heald shaft, producing a considerable force pulse. This paper is concerned with the description of dynamic behaviour of the existing design on the basis of mathematical modelling and verification of obtained results by means of experimental analysis.
\end{abstract}

\section{Keywords:}

heald, heald shaft, shedding mechanism, weaving loom, mathematical model

\section{Introduction}

The manufacturer efforts of weaving equipment is to minimise dynamic loads generated by impact effects that arise when minimising plays. One of the mechanisms most exposed to stress is the shedding motion. Its end part is the heald shaft (Figure 1). It is a holder of the healds, which are fastened to the frame of the heald shaft with a necessary designing play. The heald itself makes up a bond among a set of warp threads and a stroke function of the shedding device.The article is concerned with an analysis of the movement of the heald during the weaving cycle, with the aim to describe the mentioned system and to propose possible designing changes. The article specifies the formation of the mathematical model and its experimental verification.

Increases of effectiveness and productivity of production have been achieved largely by increasing the operating frequencies of weaving looms. However, the requirements of an optimum solution of the most stressed designing assemblies have increased consequently, because their imperfect solution reduces the performance of the loom as a whole. An increase of the output is related with a minimisation of plays. It is not possible to eliminate all the plays existing in the system. There exists a number of plays that are necessary from technological point. A careful analysis of the necessity of these plays and subsequent minimisation of their values is necessary in order to reduce the dynamic forces. By an optimisation of plays in the system, further increases of the output can be achieved Figure 1. [1, 2].

Because of the character of the heald, it is not possible to allow (under the present designing concept) for tension stress of the heald due to deformation of the rods. It would increase the probability of its destruction, bringing about an interruption of the weaving process and resulting economic losses. For this reason, due to the deformation of both the upper and lower rods (Figure 1-pos.1, 2) during the working cycle, the heald must be fastened to the frame of the heald shaft with a designing play (Figure 2). Since the heald shaft performs a feed reverse movement, the system of healds is transferred during the working cycle. The force pulse, produced after the transfer of the system of healds between the main beams of the heald shaft frame, results in an increased stress of the heald shaft frame and of the shedding mechanism as a whole.

The main purpose of the present paper is to describe dynamic behaviour of the heald shafts usually employed. The description of their behaviour is based upon a numerically solved mathematical model. The same has been compiled on the basis of a rheologic model, consisting in discretisation of the real model. The study includes also an effected experimental analysis with verification of the mathematical model.

\section{Reological model of heald shaft}

In the analysis of the system, it has been necessary to consider the compliance of the system, damping of individual elements and non-linearities occurring in the system (in particular, the designing plays). A rheologic model of the heald shaft consists in substituting a real component by means of mass points, interconnected with resilient and damping elements. The model has been devised as a one-dimensional problem with one degree of variance in the direction of movement of the heald 


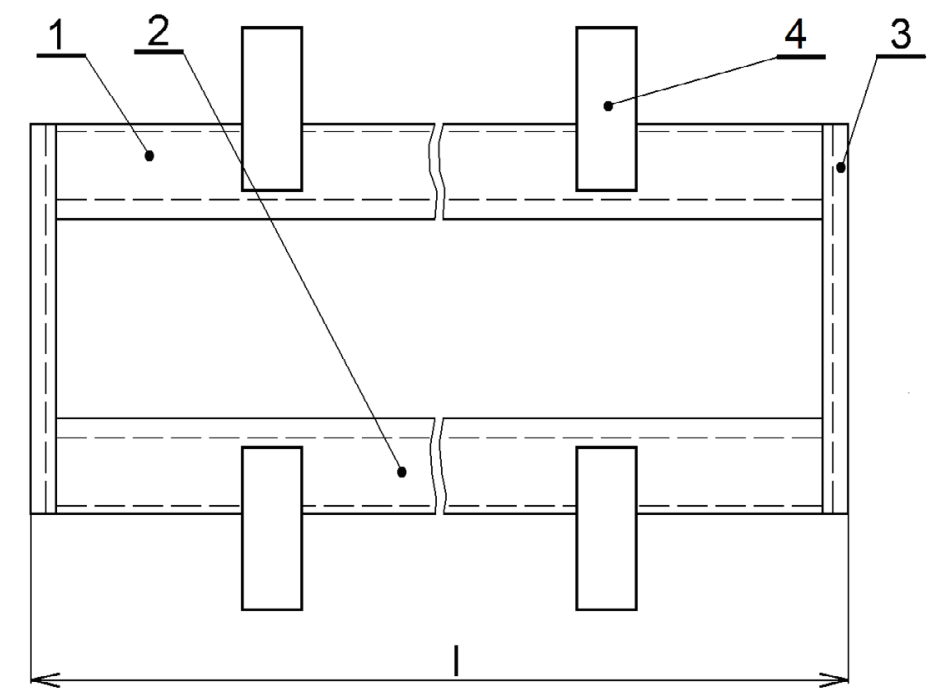

Figure 1. Heald frame

1 - Upper rod, 2- Lower rod, 3- lateral supports, 4- heald frame guide

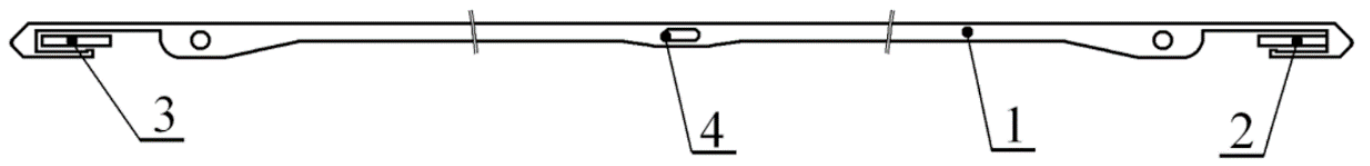

Figure 2. Heald

1 -heald body, 2,3 - support wires, 4 - thread eye

shaft. The arrangement of the rheologic model is analogous to that of the heald shaft, i.e. the rheologic model consists of two components like the real system, namely of the shaft frame and of the healds. Owing to the large number of healds applied in the shaft frame, it has been necessary to carry out a substitution (discretisation) of a certain segment of healds always with one substitutive heald of adequate parameters.

It is not possible to find a larger amount of the works dealing with this theme in the case of the heald analysis and its attaching to the carrying wire.Some analyses have been dealt with in this process experimentally $[3,4]$. In order to be able to describe the behaviour of the heald during the weaving process, it is necessary to derive a suitable mathematical model that will describe its behaviour during the operating cycle with a defined precision. The heald is influenced by a number of forces, which determine with which supporting wire it will be coupled. The most important ones are the dynamic force of the heald, the warp forces in the sense of movement of the shaft and the weight of the heald $[5,6]$.

\section{$\underline{2.1 \text { Reological model of substitutive shaft }}$}

The model of the heald shaft consists of partial subsystems, the most important one being the heald. The behaviour of the heald has been described by means of a motion equation solving its equilibrium of forces. In the calculation, the designing play have been considered in fastening the heald upon the support wire, and the size of the thread eyelet through which the thread passes. The elastic forces of warp threads are transmitted upon the rod due to the heald, and consequently, always upon one of the pair of rods only. It is possible to apply successfully the description of a mechanism based upon the method of devising motion equations by means of Lagrangian equations of the second type according to [7]. The concerned mathematical model is described with more details in $[8,9]$.

The behaviour of the heald can be described by means of an equation of motion, resolving its equilibrium of forces. In the calculation, the designing play was considered in the fastening of the heald upon supporting wire and the size of the thread eye through which the thread is passing. The elastic forces of warp threads are transferred upon the rod thanks to the heald; consequently, always upon one of the pair of the rods only.

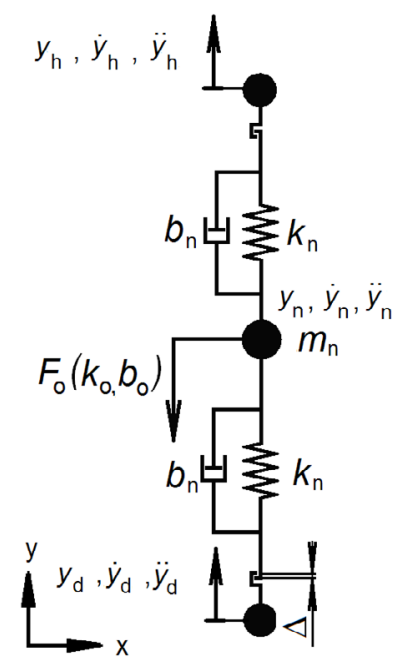

Figure 3. Mathematical model of the heald with clearance in suspension 
Figure 3 displays the mathematical model of fastening of the heald with a play where $m_{n}$ is the mass of the heald, $y_{h}, y_{h}$, $y_{h}$ the cinematic quantities of upper rod, $y_{d}, y_{d^{\prime}}, y_{d}$ - cinematic quantities of lower rod, $y_{n}, y_{n}, y_{n}$ the cinematic quantities of heald, $\mathrm{k}_{\mathrm{n}}$ the rigidity of the heald, $\mathrm{b}_{\mathrm{n}}$ the damping of the heald, $F_{D}$ the dynamic force, $F_{o}$ the force from the warp, $k_{0}$ the rigidity of the warp, $b_{\mathrm{O}}$ the damping of the warp, $\Delta$ the play in fastening the heald into the frame

In the mathematical model, the mass of the heald $m_{n}$ is concentrated into the point of the thread eye. The model of the heald is considered as a one-mass system. The heald as a body is considered to be rigid absolutely, with elastic parts. The force effect from the warp $F_{\text {。 }}$ also affects the thread eye. The body of the heald is modelled as a system spring - damper of the rigidity $k_{n}$ and damping $b_{n}$. For the diagram, according to Figure 3 , it is possible to write a differential equation in the following form:

$m_{n} \cdot \ddot{y}_{n}+b_{O} \cdot y_{n}+k_{O} \cdot y_{n}+m_{n} \cdot g=$

$=k_{n} \cdot\left(y_{h}-y_{n}\right)+b_{n} \cdot\left(\dot{y}_{h}-\dot{y}_{n}\right)-k_{n} \cdot\left(y_{n}-y_{d}\right)-b_{n} \cdot\left(\dot{y}_{n}-\dot{y}_{d}\right)$

Due to the effect of the necessary designing play, various operational states occur. The heald has a force coupling either to the upper supporting wire or to the lower one. If the coupling between the heald and one of the pair of main beams of the heald shaft is defined, we can rewrite the equation (1) to the form according to (2). By a simple conversion, we obtain the form (3), which can be solved. For solution, we have employed numerical method of Runge-Kutt of 4th order.

$$
\begin{aligned}
& m_{n} \cdot \ddot{y}_{n}=k_{O} \cdot y_{n}+m_{n} \cdot g+b_{O} \cdot \dot{y}_{n}+k_{n} \cdot\left(y_{h}-y_{n}\right)- \\
& -k_{n} \cdot\left(y_{n}-y_{d}\right)+b_{n} \cdot\left(y_{h}-y_{n}\right)-b_{n} \cdot\left(y_{n}-y_{d}\right)
\end{aligned}
$$$$
\ddot{y}_{n}=y_{n} \cdot \frac{k_{O}}{m_{n}}+\dot{y}_{n} \cdot \frac{b_{O}}{m_{n}}+g+\frac{1}{m_{n}} \cdot\left[k_{n} \cdot\left(y_{h}-y_{n}\right)-k_{n} \cdot\left(y_{n}-y_{d}\right)+\right.
$$

$+b_{n} \cdot\left(\dot{y}_{h}-\dot{y}_{n}\right)-b_{n} \cdot\left(\dot{y}_{n}-\dot{y}_{d}\right]$
In the moment of the transfer of healds between the rods, the supporting wire of the heald shaft is not influenced by elastic forces from the warp nor by dynamic forces from the healds. On the basis of the analysis in process, it is possible to determine the time distribution of the forces between the upper and lower rods as well as the moment of separation of the heald from supporting wire and the duration of the transfer. In the mathematical description, the play in the heald is defined by the difference of paths of the upper and lower rods. We take into account the assumption of the movement of the heald around the position of equilibrium, where the play in the suspension eye is formed by the shift of the upper and lower rods through $\Delta / 2$. The direction of the shift is given by the geometry of the generation of the play. The conditions for governing the calculation of the movement of the heald with a play are shown in tables 1 and 2 . For the solution of differential equations, the software MATLAB has been employed.

\section{$\underline{2.2 \text { Rheologic model of the shaft frame }}$}

The rods and the side frames of the heald shaft have been substituted with a system of mass points with mutual viscoelastic couplings. It is a symmetrical model; consequently, it is expedient to apply a half model, on condition of equal lift dependence in both the suspensions. For the mathematical description, 11 substitutive healds have been employed (Figure 4).

For the model of the shaft frame (beams), viscoelastic couplings have been employed, consisting of a tension spring and a viscose damper. The beams (rods) are created as a system of springs connected in series. For compilation of the mathematical model, the following consideration has served:

We take a prismatic beam, support it on the ends and load it with eleven single forces. On the other hand, we set up a system of eleven tension springs connected in series, loaded

Table 1. Transfer upper rod - lower rod

\begin{tabular}{|c|c|}
\hline Condition of separation & Condition of drop \\
\hline$m_{n} \cdot \ddot{y}_{n}-b_{O} \cdot \dot{y}_{n}-k_{O} \cdot y_{n}+k_{O} \cdot \delta-m_{n} \cdot g=0$ & $\mathrm{y}_{\mathrm{n}}-\mathrm{y}_{\mathrm{d}}=0$ \\
\hline
\end{tabular}

Table 2. Transfer lower rod - upper rod

\begin{tabular}{|c|c|}
\hline Condition of separation & Condition of drop \\
\hline$m_{n} \cdot \ddot{y}_{n}-b_{O} \cdot \dot{y}_{n}-k_{O} \cdot y_{n}-k_{O} \cdot \delta-m_{n} \cdot g=0$ & $\mathrm{y}_{\mathrm{n}}-\mathrm{y}_{\mathrm{h}}=0$ \\
\hline
\end{tabular}

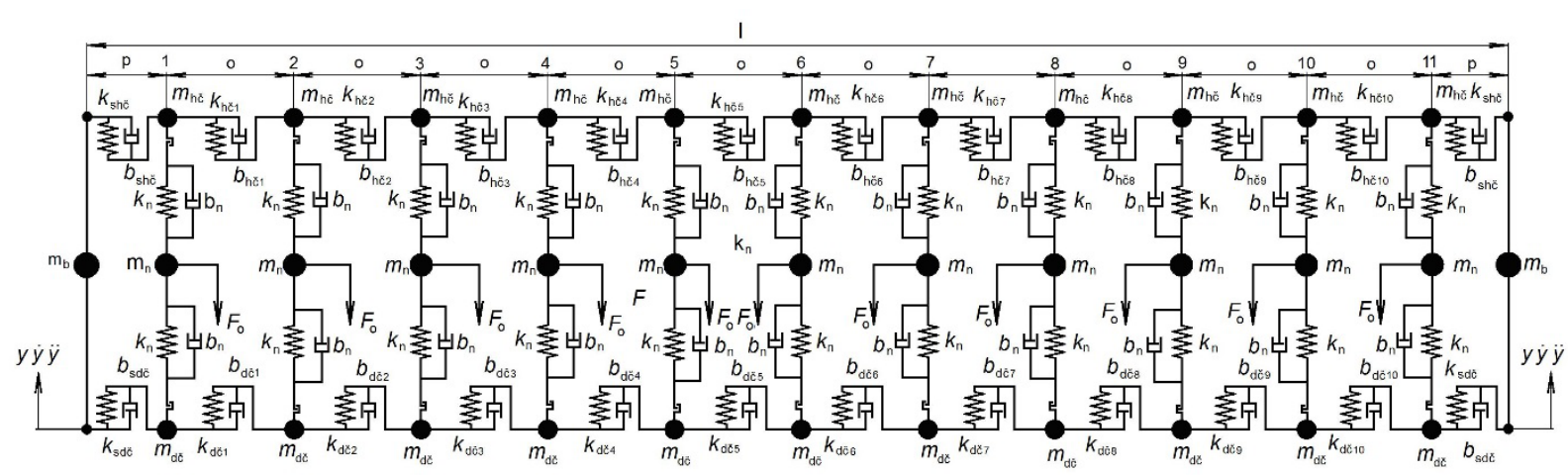

Figure 4. Reological model of heald shaft 
in the nodes with ten single forces as well. These must have such properties that the deformation curve, and/or shifts of the nodes may correspond to the shifts of the real prismatic beam. The deformation of the prismatic beam will be a smooth curve, meanwhile the deformation of the substitutive beam will be a broken line. In the analysis of this problem, we consider that with the model in question (because of small deformations) shifts take place in the direction of the axis $y$ only. The individual tension springs must be of such rigidity that the shifts of the respective nodes may be identical. This assertion is verified on the basis of equality of own frequencies of the real system and of the substitutive model. The same principle has been applied when defining the damping coefficient.

For solving the given model, Lagrangian equations of second type (4) have been employed, which after an adjustment have a general form for i-th substitute heald $(5,6)$ :

$$
\begin{aligned}
& \frac{d}{d t} \cdot\left(\frac{d K}{d \dot{q}_{i}}\right)-\frac{\partial K}{\partial q_{i}}=Q-\frac{\partial U}{\partial q_{i}}-\frac{\partial R}{\partial \dot{q}_{i}} \\
& m_{h \check{c}} \cdot \ddot{y}_{i h}=k_{h \tilde{c}(i-1)} \cdot\left(y_{(i-1) h}-y_{i h}\right)-k_{h \check{c} \bar{c}} \cdot\left(y_{i h}-y_{(i+1) h}\right)-k_{n} \cdot\left(y_{\text {ih }}-y_{\text {in }}\right)+ \\
& b_{h \bar{c}(i-1)} \cdot\left(\dot{y}_{(i-1) h}-\dot{y}_{i h}\right)-b_{h \bar{c} \tilde{c}} \cdot\left(\dot{y}_{i h}-\dot{y}_{(i+1) h}\right)-b_{n} \cdot\left(\dot{y}_{i h}-\dot{y}_{i n}\right)-m_{h \dot{c}} \cdot g
\end{aligned}
$$

$$
\begin{aligned}
m_{d \bar{c}} \cdot \ddot{y}_{i d}= & k_{d \bar{c}(i-1)} \cdot\left(y_{(i-1) d}-y_{i d}\right)-k_{d \bar{c} c} \cdot\left(y_{i d}-y_{(i+1) d}\right)+k_{n} \cdot\left(y_{i n}-y_{i d}\right)+ \\
& b_{d \bar{c}(i-1)} \cdot\left(\dot{y}_{(i-1) d}-\dot{y}_{i d}\right)-b_{d \bar{c} \bar{c}} \cdot\left(\dot{y}_{i d}-\dot{y}_{(i+1) d}\right)-b_{n} \cdot\left(\dot{y}_{i h}-\dot{y}_{i n}\right)-m_{d \bar{c}} \cdot g
\end{aligned}
$$

where $\mathrm{K}$ is the kinetic energy, $\mathrm{U}$ the potencial energy, $\mathrm{R}$ the dissipative function, $q_{i}$ the coordinate, $m_{h \check{c}}, m_{d \check{c}}$ the mass of

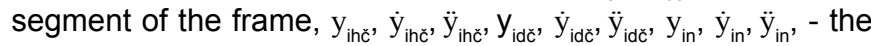
cinematic quantities of the heald and shaft frame, $\mathrm{k}_{n}, \mathrm{k}_{\mathrm{ihc}}, \mathrm{k}_{\mathrm{idc}}$ the rigidity of the heald and shaft frame, $b_{n}, b_{i h c ̌ c}, b_{i d c ́}$ the damping of the heald and shaft frame.

\section{Verification of the mathematical model}

In order to verify the results from the mathematical relations, it is necessary to compare these values with the results of measuring on a real part. In view of the very low weight of the heald (the weight of a heald ranges in order of grams), it is complicated to measure with regular experimental methods. One of the possibilities of verification of the theoretical calculation is contactless sensing by means of a high-speed camera. However, from the record obtained in this way, it is not possible to ascertain the velocity and acceleration of the drop of the heald upon the supporting wire. It is possible to compare only the moment of the drop of the heald upon supporting wire.

In order to be able to measure cinematic characteristics of the movement of the part, ultra-light acceleration sensors must be employed. In our case, an ultra-light acceleration sensor ENDEVCO 22 has been employed, the weight of which is about $0.14 \mathrm{~g}$. If we suppose the weight of one heald about two grams, it is possible to make use of this sensor, without a negative influence of the weight of the sensor itself upon the movement of the part.

For measuring the movement of the heald during the weaving cycle, a testing equipment with an approximately sinusoidal course of the lift function has been employed. The testing equipment allows for continuous adjustment of the operating r. p.m. by means of a frequency inverter. The measuring has been effected in the range of velocity of the main shaft of the weaving loom from 400 to 1000 r. p.m., corresponding to a twice the operating frequency of the shedding mechanism, i.e. from 200 up to 500 r. p.m. of the crank shaft of testing equipment. The measuring has been effected on the proper model of the shedding mechanism. In this way, the measuring has approximated considerably the conditions and simplifications applied in the model, and it has been possible to evaluate the behaviour of the shedding mechanism only, without negative effects of the other assemblies of the weaving loom. A more detailed description of this testing equipment has been given in [10].

Comparative measuring of the movement of the heald has been realised in the conditions of the laboratory of textile and singlepurpose machines. For measuring, was employed healds of the weight about $2,75 \mathrm{~g}$ (including the weight of the sensor) and with the size of the play in fastening into the frame of the heald shaft $1 \mathrm{~mm}$ and $3 \mathrm{~mm}$. For comparison purposes, the sensing of acceleration of the heald and of the heald shaft at various operating r.p.m. were effected.

It has proved possible to compare the obtained record with theoretical calculation in some crucial points. The principal point is the drop, or the separation of the heald from supporting wire of the rod, at which an undesirable force pulse is produced. Moreover, the length and number of bounces etc.

It is possible to state that the characters of the movement of the heald, ascertained by means of the analytic model and subsequently by the experiment, have been identical. There has been compared the number of skips and the time between the individual drops of the heald upon supporting wire after the transfer of the heald from one beam to the other (Table 3). Moreover, there have been compared the acceleration peaks ascertained by the calculation and measuring. These values are used in Table 4. All these values have been ascertained on the basis of statistic evaluation of data of 10 measured cycles.

Figure 5 shows the courses of acceleration of the heald that have been calculated by means of the mathematical model and the results obtained in experimental verification of the mathematical model. The moment of the drop of the heald upon supporting wire and the subsequent bounces are displayed in Figure 5. The record has been obtained at the size of the designing play of $3 \mathrm{~mm}$, and the velocity of shedding mechanism 300 r. p.m.

The mechanical properties of the yarn, which is determined by the force of the warp in the mathematical model, were determined experimentally $[11,13]$. 


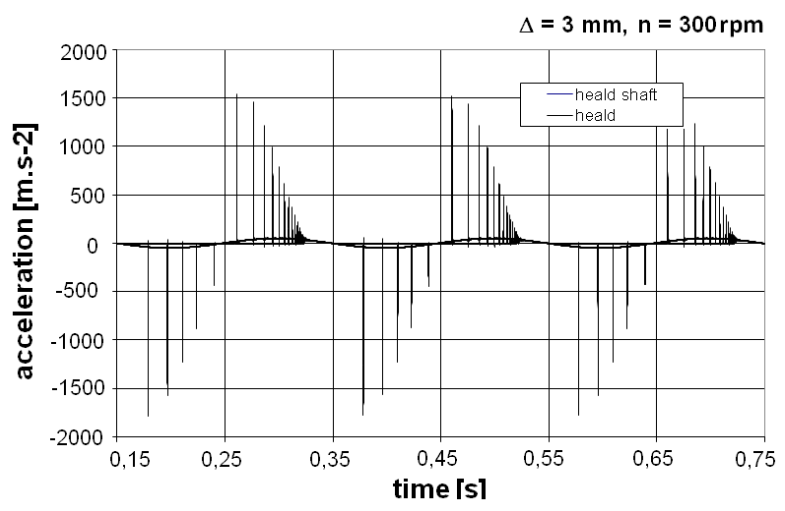

Calculation

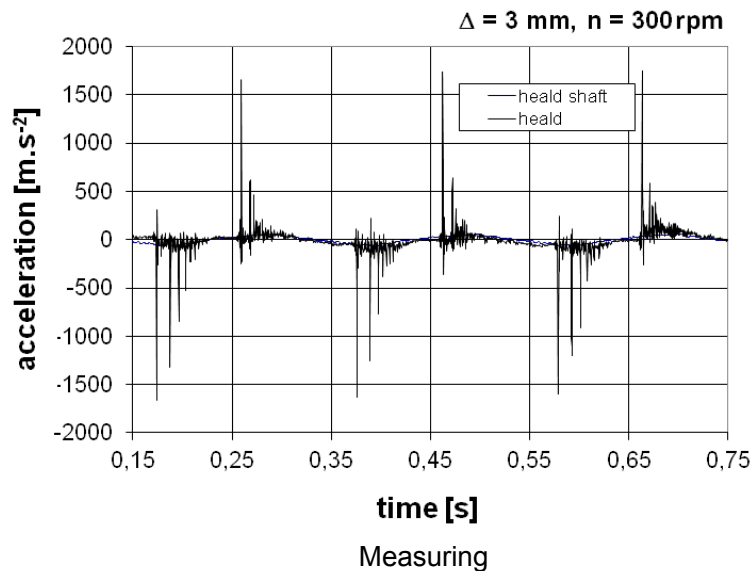

Measuring

Figure 5. Course of acceleration on the heald (about 3 revolutions of shedding mechanism)

Table 3. Bounce of the heald

\begin{tabular}{|c|c|c|c|c|}
\hline \multirow[b]{3}{*}{ Bounce No } & \multicolumn{4}{|c|}{ Duration of bounce (ms) } \\
\hline & \multicolumn{2}{|c|}{300 r.p.m. } & \multicolumn{2}{|c|}{500 r.p.m. } \\
\hline & Calculation & Measuring & Calculation & Measuring \\
\hline 1 & 14.1 & 13.5 & 9.2 & 8.7 \\
\hline 2 & 9.4 & 9.1 & 6.4 & 5.2 \\
\hline 3 & 6.3 & 5.6 & 4.3 & 4.1 \\
\hline 4 & 3.2 & 4.8 & 3.3 & 2.4 \\
\hline
\end{tabular}

Table 4. Acceleration of the heald at the drop upon supporting wire

\begin{tabular}{|c|c|c|c|c|}
\hline & \multicolumn{4}{|c|}{ Acceleration (m.s $\mathbf{~}^{-2}$} \\
\hline & \multicolumn{2}{|c|}{ Clearance 1 mm } & \multicolumn{2}{c|}{ Clearance 3 mm } \\
\hline r.p.m. & Calculation & Measuring & 1040 & 937 \\
\hline 200 & 558 & 589 & 1750 & 1767 \\
\hline 300 & 910 & 978 & 2150 & 2169 \\
\hline 400 & 1230 & 1336 & 2970 & 2891 \\
\hline 500 & 1450 & 1556 & & \\
\hline
\end{tabular}

\section{Results and discussion}

An accordance of the calculated and measured courses of kinematic quantities enables an implementation of the heald behaviour analysis during the weaving process. The compiled mathematical models enable an evaluation and analyses of the heald operation state. These operation states result from the force conditions on the heald, and they define with which carrying wire the heald will have a force bond during the weaving process. Three possible states arise from the force conditions on the heald, in which the heald can be during the working cycle:

1. The heald dynamic force is lower than the resultant forces influencing the heald. The heald changes a movement direction under the influence of pull in the warp and it moves in a direction of the carrying wire movement. The heald is drawn down on the carrying wire that is placed in the direction of the heald shaft movement (working zone No. 1, Figure 6).
2. Instability comes up in the heald behaviour during the weaving process in the case of a congruence of the heald dynamic force and resultant of the remaining forces. There is a balance of the forces affecting the heald and it can cause a multiple (accidental) detaching and fit of the heald on the carrying wire during the working cycle (working zone 2, Figure 7).

3. The heald dynamic force is higher than resultant forces influencing the heald. The movement direction of the heald and the carrying wire is identical at the moment of the shift beginning. The heald jumps over on the stave carrying wire that is turned away from the direction of the heald shaft movement (working zone No. 3, Figure 8).

The system can be tuned to favourable as well as unfavourable operation state. One of the possible examples of the system tuning was analysed. The diagram enables a determination of moment of the heald detaching and its impact on the carrying wire. 
It is clear from the described example that a transition between the fundamental operation states (transition from the working zone 1 to the working zone 3 ) is in the vicinity of 600 r.p.m. speed of the shedding mechanism. Multiple jumps of the heald among the beams of the heald shaft frame take place at this speed.

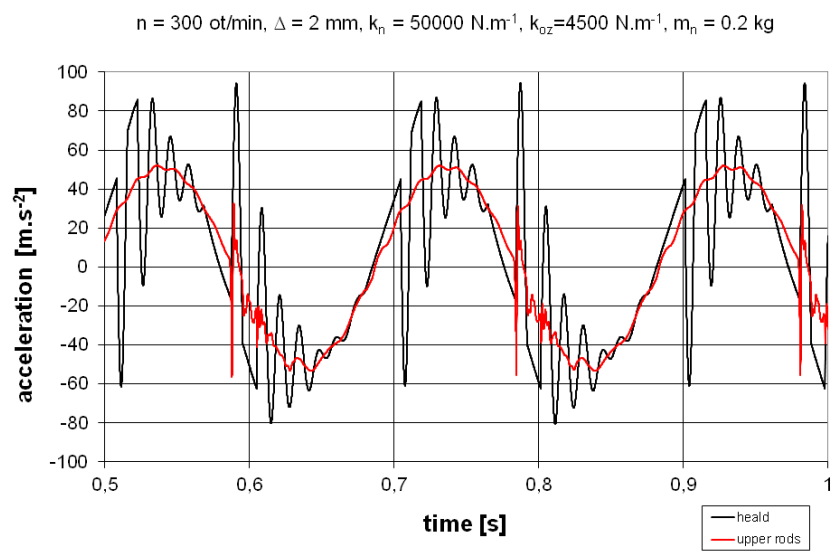

Figure 6. Time dependence of acceleration of substitute heald No. 1 - upper rod No. 1

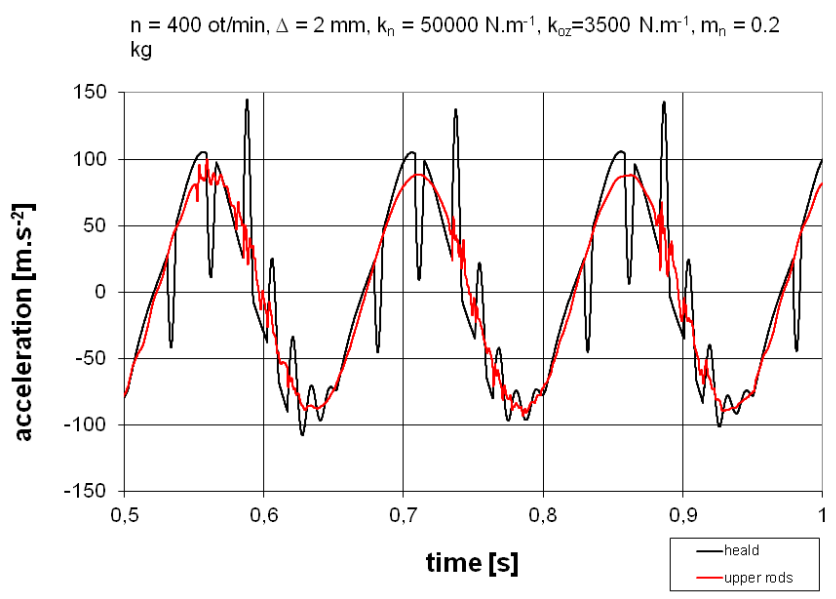

Figure 7. Time dependence of acceleration of substitute heald No. 1 -upper rod No. 1

$$
\mathrm{n}=500 \mathrm{ot} / \mathrm{min}, \Delta=2 \mathrm{~mm}, \mathrm{k}_{\mathrm{n}}=50000 \mathrm{~N} \cdot \mathrm{m}^{-1}, \mathrm{k}_{\mathrm{oz}}=3500 \mathrm{~N} \cdot \mathrm{m}^{-1}, \mathrm{~m}_{\mathrm{n}}=0.2
$$$$
\mathrm{kg}
$$

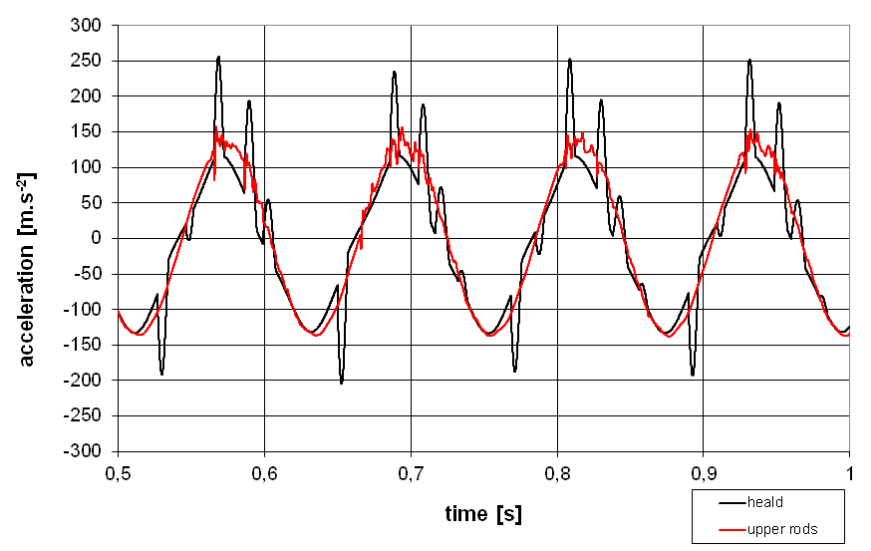

Figure 8. Time dependence of acceleration of substitute heald No. 1 -upper rod No. 1
If we increase force in the warp, we can reach an operation state when the heald moves in the working zone No. 1 within the complete range of the working speed. The value of the heald dynamic force is lower than the result of the remaining forces influencing the heald thanks to the high force in the warp, and the heald moving against the motion of the carrying wire during the shift. We can reach the same operation state also with a decrease of the heald weight. The respective heald weight can be determined from the mathematical models.

We can reach a state when there is a higher value of dynamic force than the value of the warp force within the whole range of the analysed working speed, by a decrease of force in the warp at the preservation of heald weight. The heald is operated in working zone No. 3.

\section{Conclusions}

From the detailed analysis of records of the acceleration obtained for different operating frequencies, it has been found that the moments of the drop or of the separation of the heald from supporting wire are comparable with theoretical calculation. From the record, the behaviour of the heald upon supporting wire that depends upon the operating frequency is also observed. An important factor, which can be evaluated, is the number of bounces of the heald after the drop upon supporting wire, after the transfer between the main beams of the heald shaft.

This coincidence of experimental results and calculated values obtained from the mathematical model constitutes a basic condition for a more extensive analysis of the system, with the aim to describe the behaviour of the heald during weaving cycle and to propose possible adaptations of the design.

In conclusion, it is possible to state that negative consequences of the present arrangement can be reduced through a suitable adjustment of the main parameters of dynamic system. These parameters include above all the pre-tension of the warp, the mass of the healds and operating frequencies.

\section{Acknowledgement}

The research for this paper has been supported by financial assistance of TUL in the framework of specific university research competition.

\section{References}

[1] Recep E., Gülcan Ö., Yildiray T.: Kinematics of Rotary Dobby and Analysis of Heald Frame Motion in Weaving Process. Textile Research Journal, 2008 Vol. 78, No. 12, pp. 1070-1079, USA,

[2] Eren R., Ozkan G., Mehmet Karahan M.: Comparison of Heald Frame Motion Generated by Rotary Dobby and Crank \& Cam Shedding Motions. FIBRES \& TEXTILES in Eastern Europe. Vol. 13, No. 4 2005, ISSN 1230-3666.

[3] Bílek, M., Kovář Š.: Mathematical model of the heald shaft of the weaving loom. Buletinul institutului polytehnic din 
laşi. Technical University of laşi, 2007 laşi, fasc. 5, volume 1, pp. 375-382. Romania

[4] Hong Jun, C., Li Jun, L. Analysis on Warp's Frictional Movement in the Heald Eye during Weaving Process. Advanced materials Research Volume 175-176, January 2011, Pages 490-495.

[5] Akamura, T., Kinari, T., Shimokawa, T., Miyashita, D., Mochizuki, Y., Shintaku, S.: Jumping behavior of heald in a shedding motion of loom. Journal of Textile Engineering , Volume 52, Issue 2, 2006, Pages 87-92. Japan

[6] Bilek, M., Kovář, Š.: Record of the movement of heald in the weaving loom. In IX. International Conference on the Theory of Machines and Mechanism in association with the II. CEACM Conference on Computational Mechanics 2004. Liberec : TUL, 2004, pp. 87-92.

[7] Bílek, M., Mrázek, J.: Dynamic Stress of Heald Shaft of Weaving Looms. Vlákna a textil, 1998, č.3, s. 131-134, Slovakia.

[8] Bilek, M., Skrivánek J.: Mathematical modeling of the system shedding motion - heald - warp, AUTEX Research
Journal, Vol. 14, No. 2, June 2013, Pages 42-46. ISSN 1470-9589. Poland

[9] Bílek, M.: Analysis of Head Motion during of Weaving Process, XI. International Conference on the Theory of Machines and Mechanisms, September 4-6. 2012, Liberec, Czech Republic, p. 367-373, ISBN 978-94-0075124-8, Springer Science Business Media Dordrecht

[10] Bílek, M., Kovář, Š., Mrázek, J.: Testing equipment for analysis of deformation of the frame of heald shaft of weaving looms. In. TRANSFER 2004. pp.58-61, Trenčín, Slovakia 2004

[11] Tumajer P., Ursíny P., Bílek M., Moučková E.: Use of the vibtex vibration system for testing textiles, AUTEX Research Journal, Vol. 11, No2, June 2011, ISSN 14709589,

[12] Tumajer P., Ursíny P., Bílek M., Moučková E.: Research Methods for the Dynamic Properties of Textiles. FIBRES \& TEXTILES in Eastern Europe 2011, Vol. 19, No. 5 (88) pp. 33-39.

[13] Tumajer P., Ursíny P., Bílek M., Moučková E., Pokorná M.: Influence of structure of the yarn on mechanical characteristics of yarns exposed to dynamic stress, Autex Research Journal, Volume 12, Issue 2, June 2012, Pages 44-49 